\title{
Whistleblowers : an essential resource for the sustainable prevention of risks in socio- technical systems
}

\author{
Tahar Hakim Benchekroun, ${ }^{\mathrm{a},}$, and Sandrine Pierlot ${ }^{\mathrm{b}}$ \\ ${ }^{a}$ Conservatoire National des Arts et Métiers, Centre de Recherche sur le Travail et Développement (CRTD), 41 \\ rue Gay-Lussac, 75005 Paris, France \\ ${ }^{\mathrm{b}}$ EDF-R\&D, Management des Risques Industriels / Groupe Facteurs Humains, Clamart, France
}

\begin{abstract}
Our world of industry and technology has, over the years, has seen undeniable successes in terms of safety and reliability. But major catastrophes and dramatic accidents continue, even today, to cause major human and material losses and to threaten the environment with pollution on a massive scale. Could these disasters and these accidents have been foreseen and avoided? Would it have been possible to anticipate their occurrence by detecting signals of potential hazards? It is unsettling to notice, through retrospective analysis of such events, that warnings had been issued long before the catastrophe or accident took place. This raises several questions, which we will attempt to address in this paper. Why are whistleblowers often not listened to, threatened, or simply ignored? Why are their warnings viewed as "bad omens" instead of essential resources to ensure safety? Do whistleblowers stand idly by, or do they implement individual and collective strategies to make themselves heard? Which managerial and organizational conditions are conducive to developing empowerment in whistleblowers? Based on four case studies, we attempt to address these questions, and offer a first level of analysis and explanation by proposing and defining two new concepts: operative resilience and strategic resilience.
\end{abstract}

Keywords: Whistleblowers, operative resilience, strategic resilience, risks

\footnotetext{
${ }^{*}$ Corresponding author. E-mail: tahar-hakim.benchekroun@,cnam.fr.
} 


\section{Introduction: the question at hand}

Some of the most striking accidents in recent memory include a series of train wrecks which occurred in the United Kingdom between 1998 and 2002; the crash of flight AF447 between Rio and Paris on June $1^{\text {st }} 2009$, which resulted in the deaths of 228 people; the widespread pollution following the explosion of BP's Deepwater Horizon oil drilling rig; and, more recently, the failure of the three production units in the Fukushima-Daiichi nuclear power plant in Japan, on March $11^{\text {th }}, 2009$, which has likely blighted the area surrounding the plant for a long time to come, and caused seawater pollution whose consequences are difficult to assess, both in terms of severity and durability.

Would it have been possible to foresee and avoid these catastrophes and accidents? Disturbingly, retrospective analyses carried out on several such events show that warnings had been issued regarding safety-related failures, long before the disaster or accident took place. Indeed, the Electricité de France (EDF) company and its R\&D department have, over the past several years, carried out organizational analyses of accidents occurring in various sectors of activity, confirming in many cases the existence of whistleblowers.

Such analyses, for example, highlight the key role played by Mrs. Foster, who directed the operations division of a rail company in the London area in the 1990s. In 1998, she issued several warnings regarding potential failures of train drivers to stop at a red light in the Ladbroke Grove area, all in vain. These warnings were met with the apathy and crumbling of the organization of the Greater London transportation system as it was being privatized. One year later, on October $5^{\text {th }}, 1999$, following a failure to stop at a red light in the same Ladbroke Grove area, two trains collided head-on, causing 31 fatalities and over 400 wounded [26,29].

Accident investigations carried out by the EDF R\&D department have also made it possible to highlight the key role played by Roger Boisjoly, an engineer at the Morton Thiokol company which was in charge of developing the boosters for the Challenger space shuttle, in the investigation which followed the explosion of the shuttle on takeoff, on January $28^{\text {th }} 1986$. He had voiced his opposition to the shuttle launch because the temperature had been well below the seasonal average. This made it impossible to guarantee that the O-rings would behave as expected on takeoff. This was the cause of the accident which cost seven astronauts their lives $[4,22]$. More recently, an analysis of the explosion of the BP oil refinery in Texas City [30] revealed that employees working closest to the valves had warned, in audits prior to the accident, of a decline in safety and of their fear in working every day at the facility.

These various examples suggest that, although accidents cannot be predicted with certainty in terms of their nature, importance, and date of occurrence, they can, in spite of this, potentially be foreseen [20]. If the main goal for hazardous organizations is to prevent the occurrence of accidents, whistleblowers can then truly be seen as a resource which completes industrial safety management systems. For that reason, it seems that whistleblowers are a particularly relevant subject of study.

This paper aims to discuss the status and function of whistleblowers in hazardous socio-technical systems, as well as the difficulties they encounter, and finally the conditions conducive to elaborating individual or collaborative strategies to empower them. We will also attempt to develop two new concepts which we feel are of crucial importance to account for their activity: operative resilience and strategic resilience. Our argument is based on examples from bibliographic studies and on research which we, the authors, have taken part in. First of all, it is important to provide a framework to define a "whistleblower" as the word is used in this paper, since this is a very polymorphous concept in the existing literature.

\section{Whistleblowers: a polymorphous reality}

\subsection{The concept of whistleblower: a short history and a framework}

Let us begin with a short historical reminder. In the USA, the concept of "whistleblower" emerged in the late 19th century, in the context of the War of Independence. A law was passed encouraging citizens to report any fraud involving public funds, in exchange for a monetary reward corresponding to a set percentage of the amount recovered by the State. "Whistleblower" refers here to an informant who exposes condemnable behavior (e.g. corruption, embezzlement, etc.) for the common good of the nation. In the 1970s, the concept of whistleblowing was coined in the USA by Ralph Nader, meaning "an 
act of a man or woman who, believing that the public interest overrides the interest of the organization he serves, blows the whistle that the organization is in corrupt, illegal, fraudulent or harmful activity". A more recent American law was explicitly named the Whistleblower Protection Act. Its scope is limited to civil servants, but the law covers a wide range of offences. Agents of the State can, for example, report instances of abuse of authority, endangerment of health and/or safety, bad management practices, or violations of the Law which they have witnessed in the course of their work. The passing of this law was complemented with the creation of a government agency, the Office of the Special Counsel (OSC) which has the authority to investigate complaints made by whistleblowers regarding any reprisals they have endured.

Furthermore, in 2002, the Sarbanes-Oxley Act was passed as a response to Enron-type financial scandals. The Act enforces penalties against financial fraud, and creates a structure explicitly intended to protect whistleblowers from possible reprisals [3]. This law was promulgated to encourage transparency in the financial reports of businesses quoted on the Stock Exchange. It recognizes the crucial role of employees in exposing financial wrongdoing, since it requires setting up a procedure enabling any employee to report any criminal action involving a company's bookkeeping. Article 806 of the Sarbanes-Oxley Act protects whistleblowers against any attempted retaliation by the company: any such action is viewed as a criminal offence, and punishable by a fine or prison sentence. The concept of whistleblowing or of "ethical alerts" has spread worldwide along with equivalents of the Sarbanes-Oxley Act in other nations, even though the effective setup of a whistleblowing policy is still often embryonic because of cultural or institutional obstacles.

The concept of whistleblowing relates here to illegal practices, to transgressions of the Law, and to exposing criminal wrongdoing. The related frameworks are studied in management science, as part of business ethics.

Similarly, in France, the term whistleblower has spread following the publication of the book by Francis Chateaureynaud and Didier Torny [7] which focuses on a pragmatic sociology of alerts and risk. These authors steer away from the concept of exposure, and propose a logic of the act of warning which they define thus: "in our sense, the act of alerting is a more or less extended and convoluted process, situated between two boundary figures: the call for help (in an emergency) and the ill-boding prophecy (mixing together multiple heterogeneous elements, and aiming toward an indeterminate future)". Their study focuses on "a particular sociological figure", the whistleblower, acting in response to health or environmental hazards. Their approach invites us to "pay serious attention to the processes whereby alerts are constructed, within or outside of institutional networks, and do or do not succeed in sparking debate and controversy, to speed up decision-making, reform, and alterations in plans". In this view, the whistleblower bears the characteristics of a citizen opposing institutional authorities.

The focus of our study is both complementary to and different from that of the authors mentioned above. We specifically focus on whistleblowers in the context of industrial safety. As we will see, these whistleblowers have the particular characteristic of belonging to the company or industrial sector which the alert focuses on. They are not mere citizens opposing institutional agencies as in the case of Torny and Chateaureynaud's work. Furthermore, the warnings they issue cover a domain where hazards cannot be solely attributed to transgression of a law, as in the case of the Sarbanes-Oxley Act. Their interest is not in exposing financial wrongdoing or even in earning a reward. It is instead to ensure the safety of an industrial facility, or to protect the specific "common good" that is public health, which cannot be achieved just by applying a law or regulation. Therefore, they exhibit specific characteristics which we feel must be specified, if whistleblowers are to be recognized as a resource to ensure the safety of hazardous socio-technical systems.

\subsection{Whistleblowers and resilience}

A short State of the Art of the currents of research dealing with the concept of resilience allows us to define a three-level framework to study it [21] and to see how these different approaches provide us with elements to analyze and understand whistleblower activity. The three levels are as follows: individual resilience, group resilience, and resilience in organizations.

Individual resilience is studied more particularly in psychology, psychiatry, resilience engineering and ergonomics. In the first two of these approaches, emphasis is placed on the ability to recover from adverse life situations. In the other two, the goal is to 
analyze and formulate models of the ability to anticipate, to detect early on, and to respond to variations in the operation of work systems with respect to reference situations, in order to minimize the effects of these variations on the system's dynamic stability. Their goal is also to tie together motivations, experiences, professional know-how, recognition at work, perceptions, and understandings of difficulties and hazards at work.

Resilience in a group or in a collective leads to analyzing and understanding the collective phenomena allowing operators to resist risks and hazards and to ensure a sufficient or effective level of safety: exchanging and sharing experiences; informal work rules which complement or amend formal rules when these prove to be erroneous or insufficient, or even in order to counter a lack of rules to better manage activity. The existence of superior performance and abilities in a group versus in a sum of particular individualities has been documented for some time now, both in social sciences and in ergonomics [23]. Organizational resilience itself focuses on the more global level of organizations. This level takes into account a set of entities which are internal and external to the organization under study. These entities communicate with one another, exchange data, take part in decisions, and collaborate, in order to produce and ensure the required conditions of safety. This level takes into account those characteristics of an organization which impact its capacity for resilience.

\subsection{The whistleblower: a resilient agent}

Various approaches and authors have sought to define the concept of individual resilience. These authors position themselves in the fields of psychology, psychiatry, ergonomics or resilience engineering. In this section, we attempt to identify some elements of analysis and modeling which have been produced by these various approaches, and which might help us better outline the complex and very constrained activity of whistleblowers. Werner [33] who in the 1980s carried out some research on children exposed to situations of chronic stress, observed that these children were able to face these situations and to subsequently enjoy a rich and meaningful adult life. Following this type of research, Rutter [14], one of the earliest authors to take an interest in individual resilience, views the adaptive processes used by the subject as a product of complex interactions between that subject and his environment, and as a basic mechanism of any resilient activity. Although this work focuses on the subject interacting with a social and family environment, its focus is predominantly on the mechanisms of adaptation and coping [19]. Conversely, research carried out in ergonomics and cognitive psychology, through a long series of works and papers, has sought to describe the mechanics of emergence of human error in order to prevent it [10, 12]. Very early on, this modeling of human error integrated a characterization of the operator as an actor of a situation - an actor who is able to detect and correct his own mistakes [1]. This duality in the role of the operator, who is viewed both as "an agent of system unreliability and reliability" [11] is still very prevalent in scientific, legal, and social debates and controversies. Resilience engineering is, in a way, an integrative synthesis of many different works, focusing notably on the reliability of complex dynamic systems and the prevention of major risks. It highlights the importance of the operator's ability to cope with unforeseen events $[9,5]$, through some sort of alliance between formal procedures and local autonomy, enabling the operator to regulate his own action $[16,15]$, and also the emergence of forms of system resistance against risks of failure [8]. For example, the operator's ability to recover from undesirable situations manifests, in concrete terms, in an ability, either individual or collective, to detect and recover most errors before they are of any consequence [17]. Errors and/or drifts only become a hazard when they are not detected and recuperated in time. The view put forth by these various authors is that the operator is an agent of reliability, capable of regulation [25], of anticipation strategies [10] and of collective mobilization in response to unforeseen situations $[23,2]$.

\subsection{The whistleblower: an agent of organizational resilience}

There exists no stable definition of organizational resilience. Current elements of scientific reflection suggest that organizational resilience covers both a collective aspect of activity and a second, wider, organizational aspect. The collective aspect is covered in many works on cooperation within groups, on interprofessional coordination, on occupational identity, on efficient communication in action, etc. These topics have been covered by numerous studies and publications, e.g. [23]. If we are to refer to the systemic definition of resilience proposed by the 
resilience engineering approach [6], the resilience of an organization (viewed as a system) can be described following several levels of action: anticipation, supervision and control, reaction and learning. The "surveillance/control" function is, for the moment, not much described. As we will see, whistleblowers are persons or groups of persons who, based on limited sets of signals or symptoms, is able to project himself in situations which are dangerous for the organization. He is an intermediary agent of the organization, who is able to capture signals "from the field" and to make them circulate within the organizational structure. As such, a whistleblower is a stimulating element which is instrumental in developing the "surveillance and control" function of organizational resilience in high-risk sociotechnical systems. Studies of whistleblowers thus appear to be a particularly interesting asset to begin characterizing this function.

\section{Choosing four types of alert situations}

To begin answering these various questions, we present below some succinct analyses of four alert situations. These situations differed in their context, their seriousness, and their consequences:

- The healthcare catastrophe caused by the heat wave in August 2003 in France, resulting in an excess mortality estimated to 15,000 people. Yet, warnings had been issued by healthcare professionals in the public system, both before and during the disaster, which were not taken into account in concrete terms. One of the explanations for the failure of this alert, focuses on the lack of a shared consciousness, both of the event itself and of its early signs, between professionals who went in the field to take on the dynamic complexity of the real world, and remote hierarchical and political authorities, whose role was to manage and supervise overall healthcare indices.

- The industrial crisis in the Millstone nuclear plant, leading to a decision, in January 1996, by the Nuclear Regulatory Commission (NRC) to apply to all three of the plant's production units, a policy of intensified supervision. This decision was the result of resolute, determined, and pugnacious action on the part of $\mathrm{G}$. Galatis, a senior engineer working at the plant.

- The alert issued by a corporate committee for hygiene, safety and working conditions (CHSCT) to the management of a Seveso-2 classified factory in France, regarding the nonconformity and the inefficiency of the internal operations plan (POI) which was intended for application for factory evacuation in case of a serious safety threat. This alert was the focus of much tension between factory management and the committee, which was not viewed as a competent authority in the matter of industrial hazards [24].

- Finally, the crash of the American space shuttle Columbia, and the several warnings issued by a group of engineers regarding a risk of disintegration of the shuttle upon its penetration in the atmosphere.

Through these cases, we will discuss the status and function of whistleblowers in the corresponding sociotechnical systems, the difficulties they encountered in making themselves heard, and finally the conditions which helped to construct individual and/or collaborative strategies to empower them.

\subsection{The whistleblower: an integrator of disparate events, the formulator of a prognosis - the case of the 2003 healthcare catastrophe in France}

The major heat wave which hit France in August 2003 caused the death of some 15,000 people, most of which were elderly. This tragic event led to many investigations by commissions and to many different analyses. The goal of these was to understand how an event like this could have happened in a country such as France. It was also the subject of an organizational analysis by the EDF R\&D department [28]. Beyond the organizational and institutional deficiencies of the French system of public healthcare, and beyond context-specific elements (e.g. France has a centralized culture and many people were on vacation at the time), this analysis highlights the crucial involvement of a whistleblower who tried to take on a role of anticipation in this so-called "heat wave crisis". This man, Patrice Pelloux, was at the time president of the Association of French emergency physicians, and already held undeniable media appeal. To better explain our claims, let us provide some factual elements on this crisis.

As early as June 2003, a press article by a specialist in the field warned of increased risks of mortality in the elderly in the event of a heat wave. In late July, Patrice Pelloux met with the Minister for Health and brought to his attention the high proportion of closedowns of hospital beds in the summertime (according to him, 25 to 30 percent of all beds).

On August 1-2, temperature was 4-5 degrees Celsius above seasonal average, including at nighttime. On August 5, Patrice Pelloux voiced his concerns in a widely read national newspaper: over the past 48 hours, hospitals had been handling cases 
of hyperthermia. He was interviewed on the evening news report, and exposed the fact that emergency hospital services were overrun with a sudden inflow of patients on stretchers, obstructing the corridors. Between the $4^{\text {th }}$ and the $6^{\text {th }}$ of August, the mean temperature rose a further 2-3 degrees Celsius. The nights were stifling hot, which had deteriorating effects on the health of fragile patients. On August $6^{\text {th }}$, Patrice Pelloux issued a warning to several highranking officials in healthcare structures in France, advising them of the situation. Some hospitals wished to reopen beds which had been discontinued in the summertime and to commandeer additional personnel to handle the rising numbers of patients. He succeeded in convincing national authorities of the need to launch an emergency "extreme heat plan". On August $9^{\text {th }}$, a press release was issued by the General Directorate of Healthcare, but it lacked precision regarding the risks involved and the measures that needed to be taken to protect the health of fragile patients. On August $10^{\text {th }}$, Patrice Pelloux confirmed the alert on the evening TV news. He pointed out that 50 casualties had been recorded over a four-day period in the Paris area. On August $11^{\text {th }}$, faced with a lack of response from the government, Patrice Pelloux contacted the Ministry for Health. The nights of August $10^{\text {th }}-12^{\text {th }}$ reached historic temperature records. Newspapers recorded a 50 percent increase in the daily number of hospital admissions. On August $12^{\text {th }}$, Patrice Pelloux, based on the elements that were available to him, estimated the nationwide number of victims to over one hundred. On August $13^{\text {th }}$, a nurse working in a hospital in Paris sharply addressed the Minister for Health, visiting the field: "This is shameful, it really is! No, I will not shake your hand. There is no ice left to keep the patients cool. And you come now, two weeks after the battle's over?" Returning from a vacation, the head of the General Directorate of Healthcare mentioned the possibility of 3,000 casualties because of the heat stroke. On August $14^{\text {th }}$, France exited the furnace. The inflow of emergency patients rapidly decreased. The Minister for Health admitted to the situation being a full-scale epidemic and a tragedy. The figure of 14,800 casualties was only made public on September $25^{\text {th }}$ following an epidemiological study. It was later scaled upwards to 15,000 casualties on February $20^{\text {th }}, 2004$.

\subsection{Whistleblowers at odds with organizational beliefs of "all's well": the case of the Millstone nuclear power plant}

Whistleblowers can also be found in other guises. In the case of a high-risk sociotechnical system such as a nuclear power plant or a space shuttle, George Galiatis or the DAT (Debris Assessment Team) provide good examples of whistleblowers at odds with a belief that is widely held within the system they belong to.

George Galiatis was an engineer at the Millstone nuclear power plant in the USA, in the 1990s [18]. As early as 1992, he voiced concerns to his hierarchy regarding the management of fuel waste within the plant. Management practices were not in accordance with safety requirements. In spite of hostile reactions on the part of persons in his professional environment, he took it upon himself to warn the Nuclear Regulatory Commission. This action was fruitless, since local NRC authorities had already been informed of the irregular practices in this plant, and had taken no action whatsoever. Faced with the inertia of the NRC, he contacted in 1995 an association of citizens who were hostile to nuclear power, which initiated a petition for NRC to withdraw the plant's operating permits. NRC reacted at this point. George Galiatis' "crusade" was covered by the high-profile weekly Time Magazine where the story made front page. The article discussed the plant's failures at length. The story set off a scandal which tarnished both the American nuclear industry and the NRC for its slow reaction to the warnings. In the end, the operation permits for all three of the plant's nuclear units were suspended between 1995 and 1996. Later in-depth investigations revealed serious breaches in safety measures as well as some anomalies which were even more serious than those pointed out by Galiatis. However, this action caused much prejudice to Galiatis himself. For many years, he endured hazing in the plant, and both his professional and personal lives were affected by the media attention he received.

\subsection{Whistleblowers faced with time constraints and restricted room for maneuver: the case of the Columbia space shuttle}

Another dramatic event was the disintegration of the Columbia space shuttle upon its reentry in the atmosphere in February 2003. This accident, which caused the deaths of all seven astronauts on board, could have been averted if the warning had been heard. This time, the warning was borne in NASA 
not by an isolated individual, but by a group of individuals. A team spontaneously assembled itself to assess the impact of the shard of insulating material which struck the shuttle on takeoff, within the group of specialists who were in charge of processing the images of the shuttle takeoff. They suspected an unusually large piece of debris to have caused damage in a critical area of the shuttle. They then requested, on eight separate occasions and using various organizational channels within NASA, to use space satellites to obtain complementary imagery in order to confirm or invalidate their hypothesis. This bid was unsuccessful. As the shuttle returned to earth sixteen days after takeoff, the lesion in the thermal protection material, which they had suspected, proved to be the cause of the destruction of the shuttle in temperatures exceeding 1,300 degrees Celsius when it reentered the atmosphere [27]. Whistleblowers were here confronted with NASA's organizational belief that the impact of the debris of insulating material was a common and even usual event (debris were emitted by shuttles at each takeoff). Debris posed no threat to shuttle security, since each time shuttles had been struck by it, they had returned safely from their missions. The whistleblowers' vigilance and their scientific and technical rigor had led them to increase the number of unusual and costly requests for satellite imagery because of the risk that they feared. There, again, they were at odds with organizational beliefs. But because they were unable to gather a sufficient amount of evidence in favor of their claim, and because they were unable to mobilize a decisive network of influence both inside and outside NASA (e.g. media attention), their warning was left unheeded and eventually turned to a "red alert".

\subsection{Whistleblowers faced with illegal labor practices and organizational drift: the case of a high threshold SEVESO 2-class factory}

In France, the control of major risks in industrial systems rests on the principle of multiple mechanisms, including the elaboration and application of emergency plans. Among these, the Internal Operations Plan (POI) is drafted by the factory director operating with public authorities. It defines organizational measures, methods of intervention, and means available to the factory operator to protect the personnel and surrounding environment in the event of an accident [32].
As part of an ongoing process aiming to question and test the tools in place to prevent occupational hazards, the Committee for hygiene, safety and working conditions (CHSCT) of a Seveso-2 "high threshold" class factory questioned, through the actions of its secretary, the effectiveness and operational character of the POI in the event of a major accident. It issued a warning to factory management regarding the use of this tool, specifically the fact that this tool was not mastered, even that some factory personnel were unaware of its existence. Personnel were not informed of its contents, nor were they trained to use it in the event of an incident requiring securing the buildings and evacuating the site. The alert also mentioned the fact that the Plan was very generic in nature, and did not account for some specific characteristics of the factory. For example, there were three different production units, and each unit was independent from the others in terms of production and internal organization. There was a need to take into account a possible "domino effect", i.e. the fact that accident risks might spread to the other sites by "contamination". Based on these elements and on knowledge of the potential threats to both factory personnel and external operators, the CHSCT requested an expert evaluation of the usefulness and of the operational character of the current POI plan, and of its actual use in real-world situations of site evacuation. This request for an expert evaluation was voted during a special meeting of this authority. Expert evaluation for the CHSCT is a provision of the French labor code. Its goal is to construct diagnoses and propose actions to help the CHSCT in its missions. The expert is designated by staff representatives, with no employer involvement, since the employer would be both the judge and the defendant in that event. Through its secretary, the CHSCT contacted a consultancy firm, with which it began to draft a proposal and some mission specifications. However, factory management rejected the firm's involvement, casting doubt over the CHSCT's authority over matters of industrial safety, and over the secretary's claim of links between industrial hazards and work hazards [24]. In the end, management brought the case to a court of general jurisdiction. A lengthy "tug of war" began between the factory manager and the secretary of CHSCT. Firstly, the secretary called up the collective formed by staff representatives to construct an argument based on:

a) Feedback regarding serious incidents which had been recovered just in time by supervisory staff. 
These incidents had nearly led to triggering the internal operations plan.

b) The fact that the plan contained no procedures that were known to all personnel and could be used in real-world conditions of site evacuation,

c) Warnings issued to factory management regarding potential hazards incurred by the factory, the inadequacy of tools and systems present in remote consoles, the increased physiological costs related to using the available means for personal and collective protection, (e.g. self-contained breathing equipment, distance to reach remote consoles, etc.)

Armed with these arguments justifying recourse to expert assessment, the secretary himself brought the case to a court of general jurisdiction, in order to force the employer to follow the provisions of the labor code. Having examined the proceedings on both sides (management and CHSCT), the court confirmed recourse to an expert and approved both the contents and the planned procedure. During these proceedings, the CHSCT set up a workgroup within a large workers' union, with two goals: first, to begin discussion and negotiation with the French corporation operating the company; Second, to exert pressure over the factory director to ensure that he ceased to oppose the expert evaluation, and assisted the experts in their work. Following this, the stakes of the expert assessment were constructed gradually, with involvement from all factory stakeholders. The main stake was to ensure that the intervention was carried out with involvement of all levels of factory management, as well as of factory operators, and that it excluded no-one.

\section{Characteristics of whistleblower activity}

We have presented a number of elements, based a) on a short analysis of the scientific literature focusing on whistleblowers and resilience, and b) on four case studies. Based on this, what can we identify as essential characteristics of the activity of the agents who led, in very different contexts, to alerts being issued?

The event of the heat stroke in France allows us to highlight the activity of a whistleblower, able to connect disparate elements together and to formulate a singular analysis which, in retrospect, appears to be unambiguous, accurate and relevant in its conclusion. Several separate elements were put together: high temperatures, which were covered by the media, as usual, as a drought hazard for the agricultural sector; an inflow of patients in emergency care services; the shortage of hospital beds; and warnings emanating from different hospitals. Based on these elements, the whistleblower analyzed a threat that had not been covered by the media: hyperthermia in fragile persons such as children and elderly people. He then activated his networks with a constant concern for effectiveness: TV and press media, management in the healthcare sector; and finally the Ministry of Health itself. Hs role was that of a constant relay. It was also to spur action on the part of decision-makers in policy-making institutions, who were oblivious to the scope of the disaster, by providing them with some reality "from the field".

In the case of the Millstone plant, engineer Galatis, based on his knowledge of the production units involved, of organizational drifts in fuel waste management practices which were not in accordance with health requirements - something with which everyone, it seemed, had come to terms with long ago - and of the serious consequences of these misconducts, first approached the management of these units. Management rejected Galatis' arguments and considered that the operation and safety of these units was well under control. In the face of internal contempt, and in order to make himself heard, Galatis decided to expand the range of his actions by directly involving the $\mathrm{NRC}$, which did not act because it had already been informed of these practices for the last ten years. We might infer that for plant management and for the NRC, these violations of safety rules were not viewed as serious misconducts and did not cause any serious hazard in plant operation. Convinced by his diagnosis of the situation and his prognosis of a possible catastrophe, Galatis further expanded his scope of action to civil society and public opinion, in order to be heard and taken seriously. These then exerted a strong pressure on the NRC.

As for the case of the CHSCT operating in a highthreshold Seveso 2-class factory, the committee was represented by its secretary. His activity, first of all, involved collecting a large number of facts which were evidence of a failure on the part of factory management to comply with the provisions of the Law dealing with the safe operation of the factory (e.g. failure to update the hazard studies once per 5 years, failure to update the POI plan following the integration of a new facility within factory perimeter, failure to inform and to involve the CHSCT, etc.). The CHSCT also found organizational drifts which it viewed as a hazard to internal and external staff working within the factory (e.g. safety alerts demonstrating the ineffectiveness of the Internal 
Operations Plan, failure to provide staff with a compulsory training program for major accidents, and technical dysfunctions and failures liable to set off alarms, with a possible domino effect between different production units, etc. By bringing together a wide scope of arguments, whether these were technical or regulatory and legal, the CHSCT, through action on the part of its secretary, first issued a warning to factory management, which viewed this authority as having no competence or clearance to deal with industrial hazards. Later on, it relied on Labor Law to set off a procedure naming an external assessor in order to help in its mission to prevent occupational hazards. Management initially approved this expert involvement, before opposing it and initiating proceedings in court. On a more global level, the CHSCT also called upon authorities in charge of Health and Safety issues in a major workers union, and involved it in a taskforce including designated experts as well as scientific and technical authorities in the field. Later on, contacts between the union and the corporation allowed these results and the conclusions of the expert evaluation to be made available to strategic levels of decisionmaking, superseding the clearance and room for maneuver of factory management.

Finally, in the case of the Columbia space shuttle catastrophe, in spite of conscientious, rigorous and tenacious work on the part of the team of engineers, NASA flatly refused to acknowledge their diagnosis and prognosis. Unlike the three preceding situations, whistleblowers failed to rally pressuring forces, out of a lack of any strategy aiming to involve influential players (e.g. media, civil society, political players), or simply out of a lack of time (15 days before the shuttle's return) to act in this way.

\subsection{Two new concepts of resilience: operative resilience and strategic resilience}

In all four cases presented here, whistleblowers construct an acute consciousness of the situation, based on integrating and linking together sparse sets of information of various types and from various sources. This information is often imprecise and incomplete. Whistleblowers also carry out a careful watch of facts and knowledge that relates, directly or indirectly, to the events involved. This awareness of the situation grounds possible prognoses of crises and catastrophes, and strengthens the whistleblower's argument. Except that in the cases studied here, this awareness of the situation, the diagnoses and the prognoses constructed, as well as the initiative to blow the whistle, were all viewed as "strange" by the majority; they were even rejected or considered erroneous, as a sort extravagant view of reality. When one is not listened to, the ability to be firmly convinced of the credibility and plausibility of one's diagnosis and prognosis of the situation, to be able to withstand counterarguments, pressures, attacks, and perhaps even threats and hazing, all this we feel represents aspects and processes of a resilient activity carried out by whistleblowers. We name this activity "operative resilience".

Is this operative resilience enough to make oneself heard and to shift the positions of decision-makers? In the Columbia shuttle accident, the whistleblowers remained isolated and alone. They were ultimately unable to convince their interlocutors and decisionmakers from the NASA hierarchy to alter the course of events. However, the "success" achieved by whistleblowers to make themselves heard in the three other cases, even if this happened with some delay in the case of the heat wave crisis, this delay cost many patients their lives - can be explained by operative resilience, but also by the strategies that had been set up by the whistleblowers to strengthen their own empowerment by seeking support, allies, and anti-establishment structures within various institutional, media, civil, political, or union-related spheres. The ability to resist and confront a wall of silence, refusal, rejection, attempts to discredit, contempt, threats and hazing we believe goes beyond mere operative resilience. This aspect, this process of a resilient activity which mobilizes forces of opposition in order to be able to act, we will call "strategic resilience". The concept was first developed in work in the management sciences in the USA. It refers to the ability to repeatedly overcome the blows caused by the strategies developed by the competition. Strategic resilience implies being able to anticipate evolutions in the environment, in market expectations, in the competition's strategies, and to respond to these evolutions with strategies of innovation, surprise, and alliances. We define strategic resilience as a whistleblower's ability to recover when his legitimacy, credibility and integrity are questioned, denied, or threatened by hierarchy and/or institutional decision-makers. In order for the whistleblower to be heard, empowerment requires the use of strategies to rally resources from various domains of pressure and various forces of opposition, e.g. legal, union-related, community-related, or even political. Thus defined, a whistleblower's resilience depends both on operative and strategic aspects. Both these determine his ability for anticipation, for early 
detection of potential hazards, for formulating prognoses, and for taking the initiative to warn, early on, of potentially dangerous evolutions of the system, as well as to recover by rallying forces of opposition if warnings are not taken seriously, are rejected or simply ignored.

\section{Conclusion}

This paper raises more questions than it provides answers. Indeed, we have strived to show that, in preventing accidents and major disasters, whistleblowers can have a key role in anticipating them, avoiding them, or at the very least minimizing their effects and consequences. In this mission, whistleblowers deploy an activity relying both on operative and strategic resilience. This is the only way for a whistleblower to be heard and to counter or block the succession of events which lead to crises, accidents and disasters of varying scope. However, as Chateaureynaud and Torny [7] point out, whistleblowers must make a personal commitment and put themselves on the line to get the message across. Are these conditions for the whistleblower to carry out his mission and duty of warning others, acceptable from the point of view of ergonomics? Must one absolutely put in so much effort to perform missions of such resilience to ensure long-term reliability of work systems? For example, in France, law no. 82-1097 of December $23^{\text {rd }} 1982$ recognizes "the right to alert and withdraw oneself for an employee who has reasonable cause to believe that the situation presents a grave and imminent danger to his life or health." This law is a major leap forward when it is upheld and applied to protect the health and safety of workers who feel threatened. But in the majority of situations described in this paper, their health and safety are not threatened or put at risk in a specific, isolated, direct and imminent fashion. The warning deals with risks which are liable to disrupt or endanger the whole or a part of a socio-technical system. What can be done to improve the conditions of whistleblowing? And, if need be, to protect whistleblowers as they carry out their mission and do their duty? We believe that the culture and policies of safety and security in socio-technical systems must take into account their beliefs, their strategies or even their ideologies, in approaches which organically connect top-down and bottom-up views, where the various stakeholders present in the field, such as whistleblowers, benefit from resources and means or legal devices, helping them to act and to make themselves heard.

\section{References}

[1] Blavier, E. Rouy, A.S. Nyssen, A. S. and V. de Keyser, Prospective issues for error detection. Ergonomics, 48(7), 2005, pp.758-781.

[2] Garrigou and G. Carballeda, Fiabilité organisationnelle : contributions et démarche de l'ergonomie, In Niel, E. (Eds), Maitrise des risques et sûreté de fonctionnement des systèmes de production, (2002), 1-34, Paris : Hermès.

[3] C. Didier, L'alerte professionnelle en France: un outil problématique au cœur de la RSE, Communication au $4^{\text {ème }}$ colloque du RIOOD, Université de Lille, France, 2009.

[4] D. Vaughan, The Challenger launch decision: Risky technology, culture and deviance at NASA, Chicago: University of Chicago Press, 1996.

[5] D.D. Woods and E. Hollangel, Prologue : Resilience engineering concepts, In Hollangel, E., Woods, D.D. \& Leveson, N. (Eds.). Resilience engineering, Concepts and precepts 1-6. Aldershot, UK : Ashgate, 2006.

[6] E. Hollnagel, C.P. Nemeth, and S.W.A. Dekker, Resilience engineeering perspectives: remaining sensitive to the possibility of failure, Ashgate, 2008.

[7] F. Chateaureynaud and D. Torny, Les sombres précurseurs, une sociologie pragmatique de l'alerte et du risque. Edition de l'EHESS, Paris, 1999.

[8] F. Daniellou, Le statut de la pratique et des connaissances dans l'intervention ergonomique de conception, Bordeaux: Editions du Laboratoire d'Ergonomie des Systèmes Complexes, 1992-1999.

[9] G. Grote, Rules management as a source for loose coupling in high-risk systems, In E. Hollnagel, C. P. Nemeth \& S. W. A. Dekker (Eds.), Resilience engineering perspectives: Remaining sensitive to the possibility of failure, Aldershot, UK: Ashgate, 2008, pp. 91-100.

[10] J. Leplat, Erreur humaine, fiabilité humaine dans le travail, Paris: Armand Colin, 1985.

[11] J. M. Faverge, L'homme, agent de fiabilité et d'infiabilité du processus industriel, Ergonomics, 13(3), 1970, pp.301-327.

[12] J. Reason, Human error, Cambridge : Cambridge University Press, 1990.

[13] K.E. Weick, The collapse of sensemaking in organizations: The Mann gulch disaster, Administrative science quarterly, 38(1993), pp.628-652.

[14] M. Rutter, Resilience in the face of adversity. Protective factors and rzsistance to psychiatric disorder, British Journal of Psychiatry, 147 (1985), pp.598-611.

[15] N. McDonald, Organizational resilience and industrial risk. In E. Hollnagel, D. D. Woods \& N. Leveson (Eds.), Resilience engineering: Concepts and precepts, Aldershot, UK: Ashgate, 2006, pp. 143-168.

[16] P. Le Bot, The meaning of human error in the safe regulation model for risky organizations. In E. Hollnagel (Ed.), Safer complex industrial environments: A human factors approach, Boca Raton, FL: CRC Press, 2010, pp.62-80.

[17] R. Amalberti, La maitrise des situations dynamiques, Psychologie Française, 46(2), 2001a, pp.107-118.

[18] R. Montmayeul and M. Llory, la crise à la centrale nucléaire de Millstone ou l'affaire Millstone: analyse et première synthèse, Rapport interne EDF D\&R, Clamart, France, 2000.

[19] R.S. Lazarus and S. Folkman, Stress, appraisal and coping. New York : Springer, 1984. 
[20] S. Pierlot, Y. Dien, Y and M. Llory, Are industrial accidents foreseeable?, Communication au Congrès ESREL, 7 septembre, 2009a, Prague.

[21] S. Pierlot, Y. Dien and M. Llory, Resilience and vulnerability: a complementary approach in order to diagnose the level of safety of an organization, Communication au Congrès ESREL, 7 septembre, 2009b, Prague.

[22] S. Pierlot and M. Llory, Lanceurs d'alerte et lancement d'alerte : une étude prospective, Rapport interne EDF R\&D, Clamart, France, 2005

[23] T.H. Benchekroun and A. Weill-Fassina, Le travail collectif: perspectives actuelles en ergonomie, Toulouse, Octarès Editions, 2000.

[24] T. H. Benchekroun and J.B. Hervé, Démarche d'articulation des risques industriels et des risques professionnels : l'exemple d'une usine classée Seveso II seuil haut, Institut pour la maitrise des risques (IMdR), Paris, 2008.

[25] V. De Keyser, L'erreur humaine. La Recherche, 216, 1989, pp.1444-1455.

[26] Y. Dien and M. Llory, Collision de deux trains à Paddington: analyse et première synthèse, Rapport interne EDF R\&D, Clamart, France, 2002.

[27] Y. Dien and M. Llory, Un accident organisationnel, la navette Columbia: analyse et première synthèse, Rapport interne EDF R\&D, Clamart, France, 2003.
[28] Y. Dien and M. Llory, La crise de la canicule de l'été, Rapport interne EDF R\&D, EDF R\&D, Clamart, France, 2004.

[29] Y. Dien and S. Pierlot, Cassandre au pays des risques modernes, Communication au $29^{\text {ème }}$ congrès national de Médecine et Santé au travail, 30 mai-2 juin, Lyon, France, 2006.

[30] Y. Dien, M, Llory and S. Pierlot, L'accident à la raffinerie $B P$ de Texas City: analyse et première synthèse, Rapport interne EDF R\&D, Clamart, France, 2003.

[31] Y. Dien, N. Dechy and M. Llory, Les échecs du retour d'expérience : problématiques de la formalisation et de la communication des enseignements tirés, Communication au Congrès LambdaMu, 6-10 octobre, Avignon, France, 2008.

[32] Y. Denis-Remis, Approche de la maîtrise des risques par la formation des acteurs, Mines ParisTech, Paris, 2007.

[33] Werner, The children of Kauiai : Resiliency and recovery in Adolescence and Adulthood, Journal of Adolescence and Heath, 13 (1992), pp.262-268. 